\title{
The natural course of nonculprit coronary artery lesions; analysis by serial quantitative coronary angiography
}

Jeehoon Kang ${ }^{1}$, Kyung Woo Park ${ }^{1 *}$ (D), Michael S. Lee², Chengbin Zheng ${ }^{1}$, Jung-Kyu Han ${ }^{1}$, Han-Mo Yang ${ }^{1}$, Hyun-Jae Kang ${ }^{1}$, Bon-Kwon Koo ${ }^{1}$ and Hyo-Soo Kim ${ }^{1}$

\begin{abstract}
Background: Nonculprit lesions are the major cause of future cardiovascular events. However, the natural course of nonculprit lesions and angiographic predictors of plaque progression are not well-studied. The purpose of our study was to observe the natural course of nonculprit lesions, and to identify predictors of unanticipated future events and angiographic progression in nonculprit lesions.
\end{abstract}

Methods: We analyzed 640 nonculprit lesions with a length of $\geq 2 \mathrm{~mm}$ and luminal narrowing $\geq 30 \%$ from 320 patients who had two serial angiographic follow-ups; 9 to 13 months post-PCl and 24 months post-PCl. The study endpoints were nonculprit-ischemia driven revascularization (IDR) and the rate of diameter stenosis (DS) progression. Those with progression of DS > 12\%/year were defined as 'rapid progressors'.

Results: During the median follow-up period of 737 days, 20 lesions in 20 patients (6.3\%) required nonculprit-IDR. Independent predictors of nonculprit-IDR were diabetes (hazard ratio [HR] 2.93, 95\% confidence interval [CI] 1.072-8.007, $p=0.036$ ) and lesion type B2/C (HR 4.017, 95\% Cl 1.614-9.997, $p=0.003$ ). The presence of one or both of the two major risk factors was associated with significant DS progression (3.0 $\pm 6.8 \%$ vs. $3.5 \pm 6.1 \%$ vs. $6.8 \pm 9.9 \%$ for lesions with 0,1 and both risk factors, $p<0.001$ ). Among the 640 lesions, 38 lesions (5.9\%) in 33 patients were rapid progressors, while risk factors of rapid progressors included lesion type B2/C as a lesion-related risk factor (HR 1.998, 95\% Cl 1.006-3.791, $p=0.048$ ) and diabetes mellitus as a patient-related risk factor ( $\mathrm{HR} 3.725,95 \% \mathrm{Cl} 1.937-7.538, \mathrm{p}<0.001)$. Lesions with both risk factors (type B2/C lesions in diabetic patients) were at the highest risk of rapid progression (odds ratio $3.250,95 \% \mathrm{Cl} 1$. 451-7.282), compared to type A/B1 lesions in non-diabetic patients.

Conclusion: Nonculprit-IDR was not uncommon during the 2-year follow up period in our population. The major risk factors of nonculprit lesion progression were diabetes and lesion type B2/C.

Trial registration: Retrospectively registered and approved by the institutional review board of Seoul National University Hospital (No.: 1801-138-918) on February 2nd, 2018.

Keywords: Plaque progression, Nonculprit lesion, Coronary angiography, Quantitative coronary angiography

\footnotetext{
* Correspondence: kwparkmd@snu.ac.kr; kwparkmd@hanmail.net

'Department of Internal Medicine and Cardiovascular Center, Seoul National

University Hospital, 101 Daehakro, Jongno Gu, Seoul 110-744, South Korea

Full list of author information is available at the end of the article
}

(c) The Author(s). 2018 Open Access This article is distributed under the terms of the Creative Commons Attribution 4.0 International License (http://creativecommons.org/licenses/by/4.0/), which permits unrestricted use, distribution, and reproduction in any medium, provided you give appropriate credit to the original author(s) and the source, provide a link to the Creative Commons license, and indicate if changes were made. The Creative Commons Public Domain Dedication waiver (http://creativecommons.org/publicdomain/zero/1.0/) applies to the data made available in this article, unless otherwise stated. 


\section{Background}

Nonculprit lesions account for a significant portion of future adverse cardiac events [1]. A previous study reported that nearly half of the major adverse cardiovascular events were associated with nonculprit lesions during a 3-year follow-up [2]. In the clinic, we can occasionally meet coronary artery disease patients with initially insignificant nonculprit lesions, which rapidly progress to cause ischemia despite standard medical treatment. These patients show a higher incidence of heart failure, recurrent acute coronary syndrome, leading to deterioration of the patients' quality of life [3]. Recent studies have described a few mechanisms to explain the rapid progression in coronary stenosis, including coronary vasospasm [4], a complex stenosis morphology [5], and the systemic inflammatory status [6]. However, these mechanisms are putative, and studies on the progression of nonculprit lesions are limited. Therefore, efforts to detect the predictors of nonculprit lesion progression could prevent unanticipated future events related to these lesions.

Current studies of plaque progression focus on the rupture of vulnerable plaques, which present as myocardial infarction or cardiac death [7-9]. These studies mostly used intravascular ultrasound (IVUS) or optical coherence tomography (OCT) to evaluate plaque characteristics. However, IVUS and OCT are invasive techniques which are not routinely used to characterize insignificant lesions. In fact, clinical characteristics and coronary angiography, which is the most commonly used method to initially assess coronary lesions are the only information available [10].

In this study, we analyzed insignificant, non-treated lesions, performed a longitudinal analysis using serial quantitative coronary angiography (QCA). We observed the natural course of nonculprit lesions, and identified the predictors of unanticipated future events and angiographic progression in nonculprit lesions.

\section{Methods}

\section{Study design and population}

Coronary artery disease patients, who receive PCI in our institute, were enrolled in a stent registry at the time of the index procedure (i.e. Everolimus, Zotarolimus, or Biolimus eluting stent registry). According to the protocol of the individual registries, a follow up CAG was recommended (which is not mandatory) at 9 to 13 months post-PCI. Of those that agreed to and received the first follow up angiogram, a second routine follow up angiogram was recommended at 24 months. During the study period (July 2008 to March 2013), 3044 patients were enrolled in various stent registries, and 1486 patients (48.8\%) received 9 to 13 month follow up CAG. Among these patients, 320 patients (21.9\%) had a second routine follow up CAG at 24 months post-PCI. Patients with lesions of a lesion length of $\geq 2 \mathrm{~mm}$ and luminal narrowing $\geq 30 \%$ at baseline angiography were included in the analysis. As a sensitivity analysis to check the possibility of selection bias, the baseline demographics were compared with that of the entire 3044 patients that received PCI during the study period (Additional file 1: Table S2).

The study was approved by the ethics committee and institutional review board and was conducted according to the principles of the Declaration of Helsinki. All patients provided written, informed consent for participation in the registry.

\section{Quantitative coronary angiography}

Coronary angiograms were recorded at baseline and at two serial follow-up periods. Analysis was done at the angiographic core laboratory by 3 specialized quantitative coronary angiography technicians at the Seoul National University Hospital Cardiovascular Clinical Research Center Angiographic Core Laboratory. Standard qualitative and quantitative analyses and definitions were used for angiographic analysis [11]. The ACC/AHA lesion classification system, comprising 11 angiographic variables with all lesions categorized into types (A, B1, B2 and C) were used to characterize lesions [12]. Measured variables included the reference vessel diameter, the minimal luminal diameter (MLD), and the diameter stenosis (DS). Delta DS was defined as the last DS minus the initial DS (DS at 1st follow-up when an adverse event occurred at the 1st follow-up, DS at 2nd follow-up when an adverse event occurred at the 2nd follow-up or in event-free cases.). Regarding reliability analysis, the intra-observer intraclass correlation (ICC) was 0.941 (95\% CI 0.929-0.951) and the inter-observer ICC was 0.986 (95\% CI 0.973-0.992).

\section{Study endpoints and definitions}

The study endpoints were any event of nonculprit-ischemia driven revascularization (IDR) and the rate of DS progression during the follow-up period. Revascularization was defined as ischemia-driven if there was stenosis of at least $50 \%$ of the diameter with evidence of ischemia, as documented by a positive functional study, ischemic changes on an electrocardiogram, or ischemic symptoms. In the absence of documented ischemia, DS of at least $70 \%$ was required.

The definition of 'rapid progressors' was derived using the following method. A previous study reported that the rate of non-culprit lesion related clinical event was approximately $10 \%$ during 3 years of follow-up [2]. Therefore, we analyzed the cutoff point for DS progression in the upper $10 \%$ of the population using a histogram analysis. From this analysis 'rapid progressors' were defined as patients with at least one lesion that had DS progression more than 1\% per month (or 12\% per year). This is the rate of DS progression that would turn an average lesion 
in our study, into a significant one during the 24 month follow-up period.

\section{Statistical analysis}

Continuous variables were presented as mean \pm standard deviation and were compared using Student's $t$-test or the Mann-Whitney U test. Categorical variables were presented as proportions, and chi-square test or Fisher's exact test was applied to compare differences between groups, as appropriate. A comparison of baseline and follow-up values of the QCA results were analyzed by paired $t$-tests. To determine the independent predictors of nonculprit-IDR, a Cox proportional hazard model was used. Factors included into the multivariate model were lesion type, diameter of reference vessel, lesion location of the coronary artery as lesion-related factors, and age, gender, body mass index, diabetes, hypertension, chronic kidney disease, dyslipidemia, previous MI, smoking, and clinical diagnosis of ST segment elevation myocardial infarction as clinical factors. A multiple logistic generalized estimating equations (GEE) modeling using the autoregressive structure, was performed to analyze the longitudinal changes on lesion characteristics and clinical parameters as independent variables versus the progression of nonculprit lesions as the dependent variable. Variable included in the GEE model were identical to that included in the Cox proportional hazard model. Two-sided $P$ values less than 0.05 were considered statistically significant for all tests. All statistical analyses were performed using SPSS version 20.0 (IBM Co., Chicago, IL, USA).

\section{Results}

Between July, 2008, and March, 2013, a total of 320 patients with 640 lesions were enrolled in this study. Baseline demographic and clinical characteristics, initial laboratory findings and discharge medications of the study population are summarized in Additional file 1: Table S1. To show absence of selection bias of our study population, baseline demographics were compared with the total population whom received PCI during the study period (3044 patients, during July 2008 to March 2013; Additional file 1: Table S2) [13]. The mean follow-up duration from baseline to the first and second angiography was $326 \pm 92$ days and $759 \pm 161$ days respectively (Fig. 1). Laboratory findings at the follow-up periods are shown in Additional file 1: Table S3.

\section{Baseline lesion analysis and ischemia driven revascularization}

Among the 640 baseline nonculprit lesions, 220 (34.4\%) were located in the left anterior descending coronary artery, $181(28.3 \%)$ in the left circumflex coronary artery, $237(37.0 \%)$ in the right coronary artery, and $2(0.3 \%)$ in the left main coronary artery. Also, 164 (25.6\%) were proximal lesions, 152 (23.8\%) were mid lesions, 171 (26.7\%) were distal lesions and 153 (23.9\%) were branches of epicardial coronary arteries. Baseline QCA revealed a lesion length of $11.4 \pm 7.7 \mathrm{~mm}$ with a DS of $45.1 \pm 10.5$, $29.8 \%$ had a DS $>50$, and $2.5 \%$ had a DS $>70 \%$. There was no difference in lesion character in DM and non-DM patients (Additional file 1: Table S4).

The total follow-up duration was 640.3 patient-years. During the median follow-up period of 737 days, 20 lesions in 20 patients $(6.3 \%)$ required nonculprit-IDR. Clinical and lesion characteristics between those with and without IDR are shown in Table 1. Patients who received nonculprit-IDR were more likely to have diabetes mellitus or chronic renal failure, and discharge medication pattern were similar between the two groups. Lesions that received IDR had a smaller MLD, larger DS, and were more likely to be $\mathrm{B} 2 / \mathrm{C}$ lesions.

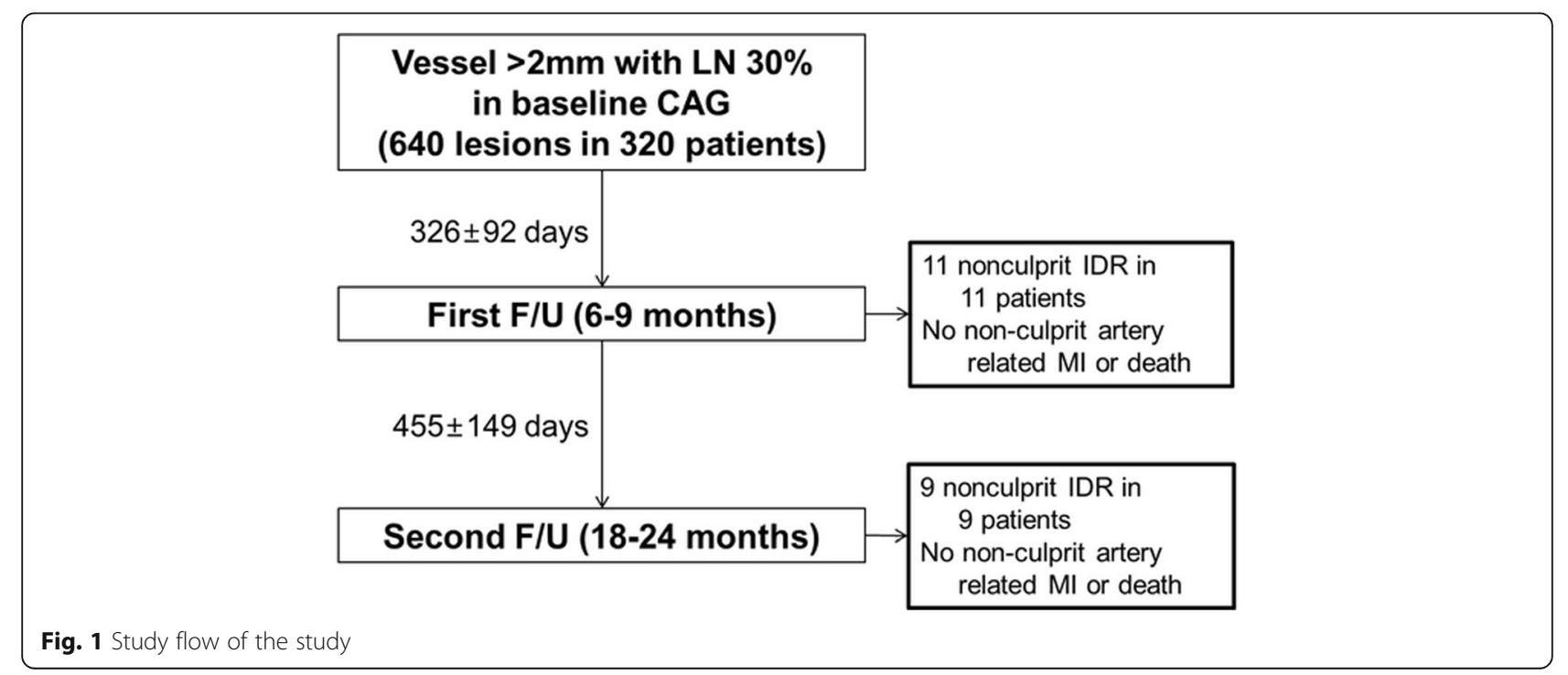


Table 1 Clinical and Lesion characteristic of lesions receiving ischemia-driven revascularization

\begin{tabular}{|c|c|c|c|}
\hline Clinical Factors & IDR (+) (20 patients) & IDR (-) (300 patients) & $P$ value \\
\hline Age (years old) & $62.5 \pm 9.9$ & $65.9 \pm 10.3$ & 0.152 \\
\hline BMI $\left(\mathrm{kg} / \mathrm{m}^{2}\right)$ & $24.3 \pm 3.2$ & $24.8 \pm 2.9$ & 0.449 \\
\hline Gender (male), n (\%) & $16(80.0)$ & $223(74.1)$ & 0.557 \\
\hline Previous PCl, n (\%) & $2(10.0)$ & $35(11.6)$ & 0.825 \\
\hline Previous CABG, n (\%) & $1(5.0)$ & $3(1.0)$ & 0.119 \\
\hline Previous MI, n (\%) & $2(10.0)$ & $22(7.3)$ & 0.661 \\
\hline Previous CHF, n (\%) & $3(1.0)$ & $0(0.0)$ & 0.816 \\
\hline Diabetes mellitus, n (\%) & $12(60.0)$ & $96(31.9)$ & 0.010 \\
\hline Hypertension, n (\%) & $13(65.0)$ & $213(70.8)$ & 0.584 \\
\hline CRF, n (\%) & $2(10.0)$ & $7(2.3)$ & 0.044 \\
\hline Dyslipidemia, n (\%) & $9(45.0)$ & $190(63.1)$ & 0.106 \\
\hline Current smoking, n (\%) & $13(65.0)$ & $164(55.2)$ & 0.394 \\
\hline FHx of CAD, n (\%) & $1(5.0)$ & $35(11.7)$ & 0.610 \\
\hline Clinical diagnosis ${ }^{a}, \mathrm{n}(\%)$ & $60.0 / 25.0 / 5.0 / 10.0$ & 64.7 / 18.7 / 10.7 / 6.0 & 0.616 \\
\hline Diagnosis of ACS, n (\%) & $8(40.0)$ & $106(35.5)$ & 0.688 \\
\hline LV ejection fraction (\%) & $61.2 \pm 7.9$ & $59.7 \pm 8.8$ & 0.482 \\
\hline WBC $\left(10^{9} / \mathrm{L}\right)$ & $7200 \pm 2200$ & $6800 \pm 2300$ & 0.550 \\
\hline Hemoglobin (g/dL) & $13.8 \pm 1.8$ & $13.5 \pm 1.8$ & 0.485 \\
\hline Creatinine(mg/dL) & $1.49 \pm 1.43$ & $1.08 \pm 0.65$ & 0.215 \\
\hline - eGFR (ml/min/1.73m²) & $63.6 \pm 28.4$ & $72.9 \pm 20.4$ & 0.056 \\
\hline HbA1c (\%) & $7.2 \pm 1.8$ & $7.0 \pm 1.0$ & 0.693 \\
\hline Total cholesterol (mg/dl) & $161 \pm 31$ & $157 \pm 40$ & 0.667 \\
\hline Triglyceride (mg/dl) & $135 \pm 56$ & $136 \pm 85$ & 0.935 \\
\hline HDL-cholesterol (mg/dl) & $44 \pm 9$ & $43 \pm 11$ & 0.585 \\
\hline LDL-cholesterol (mg/dl) & $98 \pm 31$ & $97 \pm 36$ & 0.870 \\
\hline CRP (mg/dl) & $0.41 \pm 1.13$ & $0.42 \pm 1.23$ & 0.981 \\
\hline \multicolumn{4}{|l|}{ Discharge Medications } \\
\hline - Aspirin & $20(100 \%)$ & 299 (99.7\%) & 0.796 \\
\hline - Clopidogrel & $20(100 \%)$ & 299 (99.7\%) & 0.796 \\
\hline - Beta blocker & 17 (85.0\%) & $213(71.0 \%)$ & 0.178 \\
\hline - ARB / ACE inhibitors & $13(65.0 \%)$ & $140(46.7 \%)$ & 0.112 \\
\hline - Calcium channel blockers & $5(25.0 \%)$ & $63(21.0 \%)$ & 0.672 \\
\hline - Statins & $20(100 \%)$ & $296(98.7 \%)$ & 0.603 \\
\hline - High intensity statin & $3(15.0 \%)$ & $77(25.9 \%)$ & 0.778 \\
\hline Lesion factors & IDR (+) (20 lesions) & IDR (-) (620 lesions) & $P$ \\
\hline Lesion length (mm) & $16.14 \pm 14.79$ & $11.25 \pm 7.35$ & 0.157 \\
\hline Lesion location ${ }^{\mathrm{b}},(\%)$ & $30.0 / 40.0 / 30.0 / 0.0$ & $34.5 / 27.9 / 37.3 / 0.2$ & 0.692 \\
\hline Lesion proximityc, (\%) & $20.0 / 15.0 / 30.0 / 30.0$ & $26.5 / 24.8 / 27.5 / 24.5$ & 0.703 \\
\hline Lesion type $^{\mathrm{d}}$, (\%) & $30.0 / 10.0$ / $30.0 / 30.0$ & $34.8 / 31.3 / 21.9 / 11.9$ & 0.035 \\
\hline B2/C lesion type & $12(60.0 \%)$ & $210(33.9 \%)$ & 0.016 \\
\hline Minimal lumen diameter (mm) & $1.31 \pm 0.49$ & $1.59 \pm 0.49$ & 0.013 \\
\hline Reference diameter (mm) & $2.86 \pm 0.52$ & $2.84 \pm 0.57$ & 0.868 \\
\hline
\end{tabular}


Table 1 Clinical and Lesion characteristic of lesions receiving ischemia-driven revascularization (Continued)

\begin{tabular}{llll}
\hline Clinical Factors & IDR (+) (20 patients) & IDR (-) (300 patients) & $P$ value \\
\hline Initial DS & $54.3 \pm 13.1 \%$ & $44.8 \pm 10.3 \%$ & $<0.001$ \\
Last DS & $75.8 \pm 14.8$ & $47.9 \pm 10.7 \%$ & $<0.001$ \\
Delta DS & $22.1 \pm 15.4 \%$ & $3.1 \pm 5.8 \%$ & $<0.001$
\end{tabular}

$B M I$ body mass index, $P C I$ percutaneous coronary intervention, $M I$ Myocardial infarction, $C A B G$ coronary artery bypass graft surgery, $C H F$ Congestive heart failure, $F H x$ family history, $C A D$ coronary artery disease, $L V$ left ventricle, $W B C$ white blood cell, $H D L$ high density lipoprotein cholesterol, $L D L$ low density lipoprotein cholesterol, CRP C-reactive protein, ARB Angiotensin II receptor blockers, ACE Angiotensin-converting-enzyme, DS diameter stenosis

${ }^{a}$ Clinical diagnosis: Stable angina / Unstable angina / non ST-segment elevation myocardial infarction / ST-segment elevation myocardial infarction

${ }^{b}$ Lesion location: Left anterior descending artery / Left circumflex artery / Right coronary artery / Left main coronary artery

'Lesion proximity: Proximal lesion / Mid lesion / Distal lesion / Side branch

desion type: Lesion type A / Lesion typeB1 / Lesion type B2 / Lesion type C

The independent baseline patient-level and lesion-level correlates of nonculprit-IDR were diabetes (hazard ratio $[\mathrm{HR}] 3.698,95 \%$ confidence interval $[\mathrm{CI}]$ 1.377-9.933, $p=0.009$ ) and lesion type B2/C (HR $3.510,95 \%$ CI $1.376-8.955, \mathrm{p}=0.009$ ), respectively. The rate of nonculprit-IDR for lesions increased along with the number of risk factors, showing a rate of $1.8,1.8$ and $11.9 \%$, for lesions that included 0,1 , or both risk factors, respectively. Kaplan Meier curve of nonculprit-IDR events, according to the number of risk factors is shown in Fig. 2. The combination of these two risk factors increased the risk of IDR by at least 6-fold compared with any single risk factor.

QCA analysis of the natural progression of atherosclerotic plaques

During the total follow-up period, the mean MLD decreased $(1.58 \pm 0.49 \mathrm{~mm}$ vs. $1.50 \pm 0.48 \mathrm{~mm}$ vs. $1.46 \pm$ $0.48 \mathrm{~mm}, p<0.001$, at baseline, 1 st follow-up and $2 \mathrm{nd}$ follow-up, respectively) whereas the mean angiographic DS increased $(45.1 \pm 10.6$ vs. $47.1 \pm 11.2$ vs. $48.2 \pm 11.2$, $p<0.001$, at baseline, 1st follow-up and 2nd follow-up, respectively), suggesting continuous progression of angiographic stenosis (mean delta DS: $3.73 \pm 7.09 \%$ ) A dot plot of the baseline DS and delta DS of each lesion is shown in Fig. 3. Also, the velocity of DS progression was $2.46 \pm 6.70 \% /$ year until the 1 st follow-up, $1.49 \pm$ $4.17 \% / y e a r$ from the 1 st follow-up to the 2nd follow-up period, and $2.19 \pm 5.47 \%$ /year during the total follow-up period. A histogram of the velocity of all lesions is in Additional file 1: Figure S1. Lesions with nonculprit-IDR events had a larger delta DS $(22.1 \pm 15.4 \%$ vs. $3.1 \pm 5.8 \%$, $p<0.001)$ and faster rate of DS progression $(21.12 \pm$ $17.17 \%$ /year vs. $1.58 \pm 3.14 \% /$ year, $p<0.001$ ) compared to those without events.

\section{Predictors of progression}

To investigate the predictors of DS progression, we used a GEE model for repeated measures. After correcting for the size and location of the coronary artery, male sex, low BMI $\left(<25 \mathrm{~kg} / \mathrm{m}^{2}\right)$, diabetes mellitus, and lesion type $\mathrm{B} 2 / \mathrm{C}$ were significant risk factors for a higher DS. Among these factors, diabetes mellitus and lesion type B2/C lesions showed interaction with time during the follow-up period. In other words, patients with diabetes mellitus and type B2/C lesions showed faster progression of angiographic stenosis compared with those without these factors (Additional file 1: Table S5). The mean DS and mean delta DS according to the presence of 0,1 or 2 risk

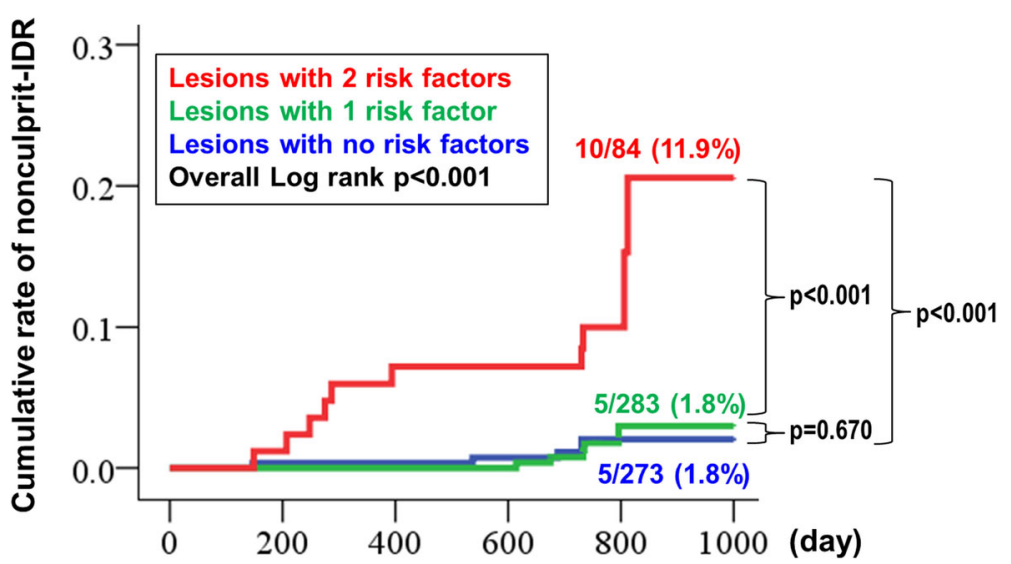

Fig. 2 Survival curve of nonculprit-IDR. Nonculprit-IDR was significantly more frequent in lesions with both risk factors (diabetes and lesion type $B 2 / C$ ) 


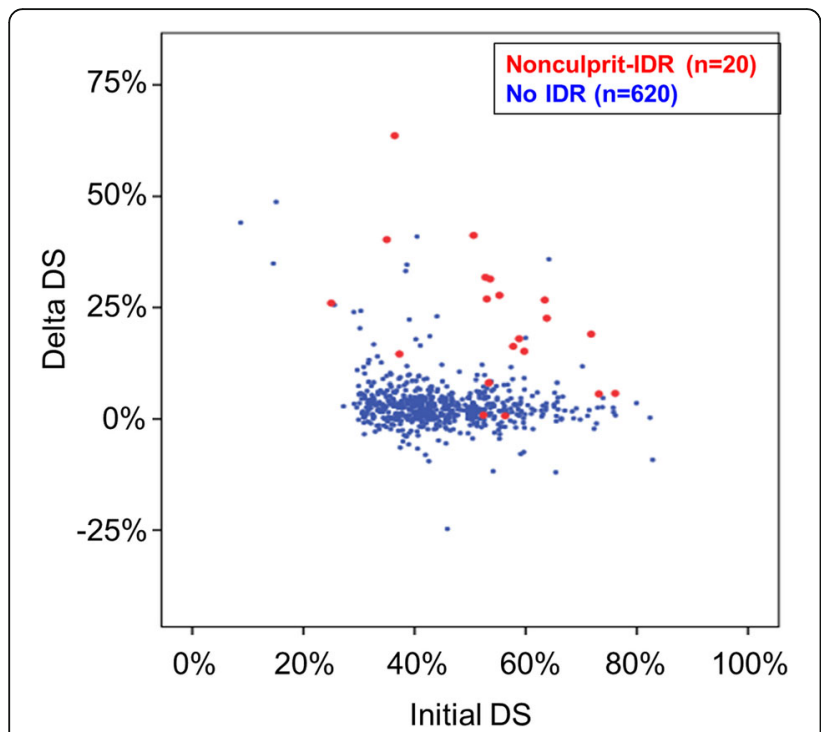

Fig. 3 Dot plot of Initial DS and Delta DS

factors are shown in Table 2. Compared with the angiographic stenosis progression of lesions with 0 or 1 risk factor, those with 2 risk factors had a significantly faster progression (delta DS of lesions with both risk factors: 2.3-fold larger compared to those with no risk factors and 1.9-fold larger compared to those with 1 risk factor). This was also consistent with comparison of the velocity of DS progression, where lesions with both risk factors showed a 2.8-fold larger velocity of DS progression.
Among the 640 lesions, 38 lesions (5.9\%) in 33 patients were defined as rapid progressors, defined as a progression of DS more than $1 \%$ year month or more than $12 \%$ per year. The GEE model for repeated measures revealed lesion type $\mathrm{B} 2 / \mathrm{C}$ as a lesion-related risk factor for rapid progressors with a OR 2.139 (95\% CI 1.066-4.294, $p=0.032$ ) and diabetes mellitus as a patient-related risk factor (OR 2.782, 95\% CI 1.3495.737, $p=0.006$ ). Lesions with both risk factors of diabetes and lesion type $\mathrm{B} 2 / \mathrm{C}$ were at the highest risk of rapid progression $(13 / 273$ [4.8\%] vs. $12 / 283$ [4.0\%] vs. $13 / 84$ [15.5\%], $p<0.001$ for lesions with 0,1 , and 2 risk factors, respectively), with an odds ratio of 3.250 (95\% CI, 1.451-7.282), compared to type A/B1 lesions in non-diabetic patients (Fig. 4).

\section{Discussion}

In this study, the natural course of initially insignificant coronary artery lesions $6.3 \%$ of patients underwent nonculprit-IDR. Diabetes and lesion type B2/C were the major independent risk factors of nonculprit-IDR. The DS increased by $3.7 \pm 7.1 \%$ (rate of $2.19 \pm 5.47 \%$ per observed year) during the total follow-up period. The presence of both major risk factors resulted in a 2.8 -fold faster DS progression compared to one or no risk factor. Rapid progression was found in $5.9 \%$ of lesions. Diabetes and lesion type $\mathrm{B} 2 / \mathrm{C}$ were again the major predictors of rapid progression, and lesions with both risk factors

Table 2 Initial and final Diameter Stenosis according to number of risk factors

\begin{tabular}{|c|c|c|c|c|c|}
\hline & Group $1^{a}$ & Group $2^{a}$ & Group $3^{a}$ & $P$ value & \\
\hline & No risk factors & 1 risk factor & 2 risk factors & & \\
\hline Initial DS & $42.9 \pm 9.6 \%$ & $46.0 \pm 11.0 \%$ & $48.8 \pm 10.5 \%$ & Overall & $<0.001$ \\
\hline & & & & Group 1 vs. Group 2 & 0.001 \\
\hline & & & & Group 2 vs. Group 3 & 0.075 \\
\hline & & & & Group 1 vs. Group 3 & $<0.001$ \\
\hline Final DS & $46.0 \pm 9.7 \%$ & $49.5 \pm 12.0 \%$ & $55.5 \pm 14.6 \%$ & Overall & $<0.001$ \\
\hline & & & & Group 1 vs. Group 2 & 0.001 \\
\hline & & & & Group 2 vs. Group 3 & $<0.001$ \\
\hline & & & & Group 1 vs. Group 3 & $<0.001$ \\
\hline Delta DS & $3.0 \pm 6.8 \%$ & $3.5 \pm 6.1 \%$ & $6.8 \pm 9.9 \%$ & Overall & $<0.001$ \\
\hline & & & & Group 1 vs. Group 2 & 0.703 \\
\hline & & & & Group 2 vs. Group 3 & 0.001 \\
\hline & & & & Group 1 vs. Group 3 & $<0.001$ \\
\hline Velocity of DS progression & $0.150 \pm 0.402 \% /$ month & $0.154 \pm 0.298 \% /$ month & $0.422 \pm 0.956 \% /$ month & Overall & $<0.001$ \\
\hline & & & & Group 1 vs. Group 2 & 0.995 \\
\hline & & & & Group 2 vs. Group 3 & $<0.001$ \\
\hline & & & & Group 1 vs. Group 3 & $<0.001$ \\
\hline
\end{tabular}

aGroup 1 implies those with diabetes mellitus (-) and B2C lesions (-). Group 2 implies diabetes mellitus (+), B2C lesions (-) or diabetes mellitus (-), B2C lesions (+) and Group 3 implies diabetes mellitus (+) \& B2C lesions (+) 


\section{Rate of Rapid Progressors}

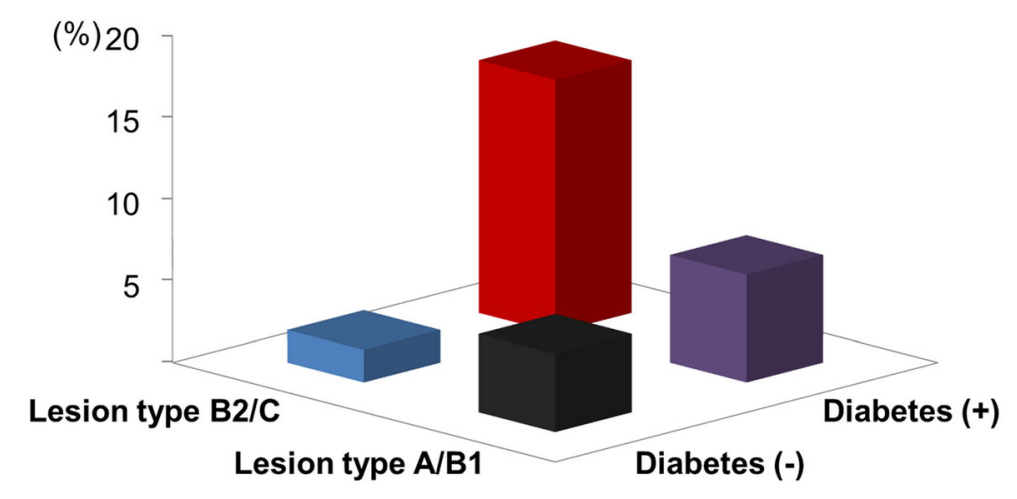

\begin{tabular}{c|c|cc|c}
\multicolumn{2}{c|}{} & \multicolumn{2}{|c|}{ Lesion type } & \multirow{2}{*}{ Overall P by $\mathbf{X}^{2}$} \\
\cline { 3 - 4 } \multicolumn{2}{c|}{} & A / B1 & B2 / C & \\
\hline \multirow{2}{*}{ DM } & $(-)$ & $4.8 \%(13 / 273)$ & $2.0 \%(3 / 147)$ & $<0.001$ \\
& $(+)$ & $6.6 \%(9 / 136)$ & $15.5 \%(13 / 84)$ & \\
\hline
\end{tabular}

Fig. 4 Rate of 'Rapid Progressors' by risk factor. Significantly more 'Rapid progressors' in lesions with both risk factors (diabetes and lesion type $B 2 / C$ )

showed a 3.25-fold higher risk of rapid progression, compared to those with no risk factors.

\section{Natural history of coronary plaques}

The pathophysiology of coronary plaque formation has been studied for decades. Inflammation was identified as the primary driving force for activation and proliferation of smooth muscle cells, a processes mediated by growth factors. [14] Lesion progression can be induced by lipid accumulation, endothelial damage, or plaque erosion which involves many factors such as clinical risk factors of the individual, mechanical forces, etc. [15] Progression to a vulnerable plaque (known as thin cap fibroatheroma) [16], or injury such as deep plaque fissures or ulcerations, can cause acute coronary syndrome. [17]

Imaging techniques such as IVUS and OCT have been used to evaluate lesions and provide valuable information on plaque and lumen character. For example, the PROSPECT (Providing Regional Observations to Study Predictors of Events in the Coronary Tree) trial demonstrated that vulnerable plaques which are most likely to cause sudden unexpected adverse cardiac events can be pre-identified through IVUS imaging techniques. [2] In this study, the 3-year cumulative rate of major adverse cardiovascular events was $20.4 \%$, among which, $11.6 \%$ were related to non-culprit lesions. Predictors for non-culprit lesions related events included insulin dependent diabetes and previous PCI as patient related factors, and a plaque burden of $70 \%$ or greater or a minimal luminal area of $4.0 \mathrm{~mm}^{2}$ or less or thin-cap fibroatheromas lesions as lesion related factors. In addition, the PROSPECT II trial is ongoing trial which will assess the ability of intracoronary near infrared spectroscopy (NIRS) to identify vulnerable plaques which subsequently lead to coronary events.

However, even these sophisticated imaging tools have shortcomings. For example invasive imaging tools cannot evaluate distal lesions, increases the time and expense of PCI and may cause coronary dissection or plaque erosion through physical contact. Also, evaluating the entire coronary vasculature with these tools is a significant clinical burden to both the clinician and patient. [18] Therefore, we still need more feasible angiographic standards for lesion evaluation.

In our study, we analyzed non-culprit lesions with serial coronary angiography and QCA, which permitted more detailed analysis. Compared to the PROSPECT trial, we could analyze the angiographic progression in every non-culprit lesion, including those which were not related to clinical events. We calculated the average angiographic progression rate in non-culprit lesions, the predictors of rapid progression, and also the predictors of clinical events. Regarding the fact that IVUS cannot be performed in every patient that we meet in the clinic, our results may give clinicians a more practical guideline for future events related with non-culprit lesions.

\section{Predictors of revascularization in nonculprit coronary plaques}

Our population, in general, was receiving optimal medical therapy, with dual antiplatelet agents and lipid lowering agents. Previous studies have shown that statins 
could induce atheroma regression in coronary artery disease patients. $[19,20]$ Regarding lipid lowering agents, 93.8\% were on statin, and the LDL level was very well-controlled, being $97 \pm 35 \mathrm{mg} / \mathrm{dL}$ at the initial state and $67 \pm 22 \mathrm{mg} / \mathrm{dL}$ and $65 \pm 20 \mathrm{mg} / \mathrm{dL}$ at the 1 st and 2nd follow-up respectively, suggesting that the study population, on average, were receiving appropriate statin therapy.

During the 2-year follow-up period, nonculprit-related events occurred in $6.3 \%$ of the patients, which were all revascularization events with no events of MI or nonculprit-related cardiac death. This was a similar rate to a previous study, where revascularization occurred in 10.5\% during a 3-year follow-up. [2] Among lesion factors showing difference between those who and who did not experience nonculprit-IDR (i.e. smaller initial MLD, larger DS and had a higher proportion of lesion type B2/ C), we were able to identify one lesion characteristic that was a significant predictor of subsequent events: lesion type B2/C. Diabetes was the only significant clinical factor to predict nonculprit IDR.

\section{Lesion progression and rapid progressors}

Nonculprit lesions showed progression in DS at a velocity of approximately $2.2 \%$ /year. Factors associated with a faster progression over the follow-up period, were identical to those risk factors of nonculprit-IDR; diabetes and lesion type B2/C. It is well-known that local factors, such as tortuosity and irregular contours of the lesion (incorporated in the lesion type definition [12]) and systemic factors, such as diabetes both are related to lesion progression. [21, 22] From our result, lesions with risk factors had a 1.5-fold faster velocity of DS progression, compared to those without risk factors.

Among the total lesions, 5.9\% were rapid progressors, with a progression of DS more than $1 \%$ year month or more than $12 \%$ per year. From the histogram of velocity of DS progression, there was a distinct group of lesions with faster progression. Predictors of rapid progression were identical to that of nonculprit-IDR (i.e. diabetes and lesion type $\mathrm{B} 2 / \mathrm{C}$ ); however there was a distinct pattern in the effect size of each risk factor. For predictors of nonculprit-IDR, lesion type B2/C had a larger effect size compared to diabetes, whereas predictors of rapid progressors, the effect size of diabetes was larger than that of lesion type B2/C. This can be partially explained by the character of the outcomes; nonculprit-IDR and rapid progressors. As nonculprit-IDR is outcome that embodies the discretion of the operator, high risk morphology of the coronary lesion, such as lesion type $\mathrm{B} 2 / \mathrm{C}$, could have influenced the procedure. On the other hand, rapid progressors was an angiographic finding which is free from any interference by the eye of the operator. Therefore, a more 'ugly' morphology of the nonculprit lesion, could have had more influence on nonculprit-IDR, compared to rapid progressors.

\section{Limitation}

Although we performed a serial angiographic analysis of nonculprit lesion, our study has several important limitations. One inherent limitation is due to angiography itself. Even to the most experienced eye, angiography is a lumenogram yielding little insight into plaque composition or lesion pathology. It is well-known that plaques that show different composition have different outcomes, and that plaque composition does not always correlate with DS. Information regarding plaque character is something that is unobtainable from angiography. Also, other than morphology, fluid mechanics such as coronary wall shear stress is known to be associated with plaque progression, which was not analyzed. Second, due to the retrospective nature of our study, there could have been a selection bias in patient selection. We compared the baseline clinical characteristics with the total parent population whom received PCI during the study period, and we found minimal difference between the two populations. However, we cannot complete deny possibilities of other selection bias within our study population.

\section{Conclusion}

Nonculprit-IDR was not an uncommon event during the 2 -year follow up period in our population. Diabetes and lesion type $\mathrm{B} 2 / \mathrm{C}$ are the major risk factors for nonculprit lesion IDR. Also, regarding angiographic progression, lesions with both risk factors showed a significantly rapid progression in DS compared to those with one or no risk factor.

\section{Additional file}

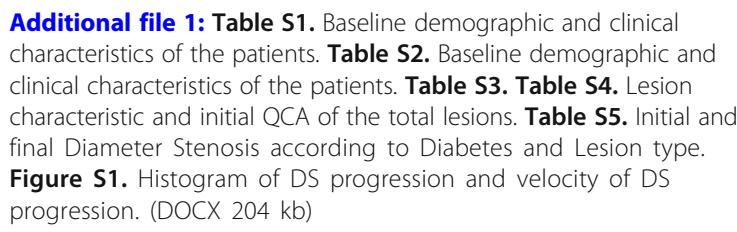

\section{Abbreviations}

CAG: Coronary angiography; Cl: Confidence interval; DS: Diameter stenosis; GEE: Generalized estimating eqs.; HR: Hazard ratio; ICC: Intraclass correlation; IDR: Ischemia driven revascularization; IVUS: Intravascular ultrasound; MLD: Minimal luminal diameter; NIRS: Near infrared spectroscopy; OCT: Optical coherence tomography; OR: Odds ratio; PCl: Percutaneous coronary intervention; QCA: Quantitative coronary angiography

\section{Availability of data and materials}

The datasets generated and/or analysed during the current study are not publicly available because the information includes patient's personal information, which should be protected in regards of the 'Personal Information Protection Act'. However, the dataset of the current study may 
be available from the corresponding author on reasonable request, after anonymized.

\section{Authors' contributions}

JK, KWP and HSK made substantial contributions to conception and design $J K H, H M Y, H J K$ and BKK contributed in acquisition of data and analysis of data; JK, KWP and CZ have been involved in drafting the manuscript, MSL, $\mathrm{JKH}$ and BKK critically revised the manuscript for important intellectual content; KWP and HSK gave final approval of the version to be published. Each author has participated sufficiently in the work, and takes public responsibility for appropriate portions of the content. All authors read and approved the final manuscript.

\section{Ethics approval and consent to participate}

The study was approved by the ethics committee and institutional review board or Seoul National University and was conducted according to the principles of the Declaration of Helsinki. All patients provided written, informed consent for participation in the registry.

\section{Consent for publication}

Not applicable.

\section{Competing interests}

The authors declare that they have no competing interests.

\section{Publisher's Note}

Springer Nature remains neutral with regard to jurisdictional claims in published maps and institutional affiliations.

\section{Author details}

${ }^{1}$ Department of Internal Medicine and Cardiovascular Center, Seoul National University Hospital, 101 Daehakro, Jongno Gu, Seoul 110-744, South Korea. ${ }^{2}$ Division of Cardiology, University of California Los Angeles Medical Center, Los Angeles, CA, USA.

Received: 27 March 2018 Accepted: 21 June 2018

Published online: 28 June 2018

\section{References}

1. Gershlick AH, Khan JN, Kelly DJ, Greenwood JP, Sasikaran T, Curzen N, Blackman DJ, Dalby M, Fairbrother KL, Banya W, et al. Randomized trial of complete versus lesion-only revascularization in patients undergoing primary percutaneous coronary intervention for STEMI and multivessel disease: the CVLPRIT trial. J Am Coll Cardiol. 2015;65(10):963-72.

2. Stone GW, Maehara A, Lansky AJ, de Bruyne B, Cristea E, Mintz GS, Mehran R, McPherson J, Farhat N, Marso SP. Others. A prospective natural-history study of coronary atherosclerosis. N Engl J Med. 2011;364(3):226-35.

3. Xin H, Gong HP, Cai SL, Ning XF, Liu S, Chen ZY, Lian ZX, Zhang R, Zhang QF, Kang WQ, et al. Elevated lipoprotein-associated phospholipase A2 is associated with progression of nonculprit lesions after percutaneous coronary intervention. Tohoku J Exp Med. 2013;230(2):97-102.

4. Nobuyoshi M, Tanaka M, Nosaka H, Kimura T, Yokoi H, Hamasaki N, Kim K, Shindo T, Kimura K. Progression of coronary atherosclerosis: is coronary spasm related to progression? J Am Coll Cardiol. 1991;18(4):904-10.

5. Kaski JC. Rapid coronary artery disease progression and angiographic stenosis morphology. Ital Heart J. 2000;1(1):21-5.

6. Nakachi T, Kosuge M, Hibi K, Ebina T, Hashiba K, Mitsuhashi T, Endo M, Umemura S, Kimura K. C-reactive protein elevation and rapid angiographic progression of nonculprit lesion in patients with non-ST-segment elevation acute coronary syndrome. Circ J. 2008;72(12):1953-9.

7. Puri R, Nicholls SJ, Ellis SG, Tuzcu EM, Kapadia SR. High-risk coronary atheroma: the interplay between ischemia, plaque burden, and disease progression. J Am Coll Cardiol. 2014;63(12):1134-40.

8. Sharif F, Murphy RT. Current status of vulnerable plaque detection. Catheter Cardiovasc Interv. 2010;75(1):135-44.

9. Toutouzas K, Benetos G, Karanasos A, Chatzizisis YS, Giannopoulos AA, Tousoulis D. Vulnerable plaque imaging: updates on new pathobiological mechanisms. Eur Heart J. 2015;36(45):3147-54.

10. Anderson RD, Pepine CJ. Coronary angiography: is it time to reassess? Circulation. 2013;127(17):1760-2.
11. Lansky AJ, Dangas G, Mehran R, Desai KJ, Mintz GS, Wu H, Fahy M, Stone GW, Waksman R, Leon MB. Quantitative angiographic methods for appropriate end-point analysis, edge-effect evaluation, and prediction of recurrent restenosis after coronary brachytherapy with gamma irradiation. J Am Coll Cardiol. 2002;39(2):274-80.

12. Scanlon PJ, Faxon DP, Audet AM, Carabello B, Dehmer GJ, Eagle KA, Legako RD, Leon DF, Murray JA, Nissen SE, et al. ACC/AHA guidelines for coronary angiography: executive summary and recommendations. A report of the American College of Cardiology/American Heart Association task force on practice guidelines (committee on coronary angiography) developed in collaboration with the Society for Cardiac Angiography and Interventions. Circulation. 1999;99(17):2345-57.

13. Park KW, Kang J, Kang SH, Ahn HS, Lee HY, Kang HJ, Koo BK, Chae IH, Youn TJ, Oh BH, et al. Usefulness of the SYNTAX and clinical SYNTAX scores in predicting clinical outcome after unrestricted use of sirolimus- and everolimus-eluting stents. Circ J. 2013;77(12):2912-21.

14. Libby P. Inflammation in atherosclerosis. Nature. 2002;420(6917):868-74.

15. Yahagi K, Kolodgie FD, Otsuka F, Finn AV, Davis HR, Joner M, Virmani R. Pathophysiology of native coronary, vein graft, and in-stent atherosclerosis. Nat Rev Cardiol. 2016;13(2):79-98.

16. Narula J, Nakano M, Virmani R, Kolodgie FD, Petersen R, Newcomb R, Malik S, Fuster V, Finn AV. Histopathologic characteristics of atherosclerotic coronary disease and implications of the findings for the invasive and noninvasive detection of vulnerable plaques. J Am Coll Cardiol. 2013:61(10):1041-51.

17. Fuster V, Badimon L, Badimon JJ, Chesebro JH. The pathogenesis of coronary artery disease and the acute coronary syndromes (1). N Engl J Med. 1992;326(4):242-50.

18. Kang J, Jeon KH, Kim SW, Park JJ, Yoon CH, Suh JW, Cho YS, Youn TJ, Chae $\mathrm{IH}$, Choi DJ. Evolution of nonculprit coronary atherosclerotic plaques assessed by serial virtual histology intravascular ultrasound in patients with ST-segment elevation myocardial infarction and chronic total occlusion. Coron Artery Dis. 2016;27(8):650-7.

19. Nicholls SJ, Tuzcu EM, Sipahi I, Grasso AW, Schoenhagen P, Hu T, Wolski K, Crowe T, Desai MY, Hazen SL, et al. Statins, high-density lipoprotein cholesterol, and regression of coronary atherosclerosis. JAMA. 2007;297(5):499-508.

20. Raber L, Taniwaki M, Zaugg S, Kelbaek H, Roffi M, Holmvang L, Noble S, Pedrazzini G, Moschovitis A, Luscher TF, et al. Effect of high-intensity statin therapy on atherosclerosis in non-infarct-related coronary arteries (IBIS-4): a serial intravascular ultrasonography study. Eur Heart J. 2015;36(8):490-500.

21. Nicholls SJ, Tuzcu EM, Kalidindi S, Wolski K, Moon KW, Sipahi I, Schoenhagen P, Nissen SE. Effect of diabetes on progression of coronary atherosclerosis and arterial remodeling: a pooled analysis of 5 intravascular ultrasound trials. J Am Coll Cardiol. 2008;52(4):255-62.

22. Burke AP, Kolodgie FD, Zieske A, Fowler DR, Weber DK, Varghese PJ, Farb A, Virmani R. Morphologic findings of coronary atherosclerotic plaques in diabetics: a postmortem study. Arterioscler Thromb Vasc Biol. 2004;24(7):1266-71.

\section{Ready to submit your research? Choose BMC and benefit from:}

- fast, convenient online submission

- thorough peer review by experienced researchers in your field

- rapid publication on acceptance

- support for research data, including large and complex data types

- gold Open Access which fosters wider collaboration and increased citations

- maximum visibility for your research: over $100 \mathrm{M}$ website views per year

At BMC, research is always in progress.

Learn more biomedcentral.com/submissions 